Revista

Ibero-Americana

de Estratégıa

\title{
A ESTRATÉGIA DE INTERNACIONALIZAÇÃO DE NEGÓCIOS NA PERSPECTIVA DA TRADUÇÃO CULTURAL: O CASO DA INDICAÇÃO GEOGRÁFICA NO AGRONEGÓCIO
}

\section{THE INTERNATIONALIZATION OF BUSINESS STRATEGY IN THE PERSPECTIVE OF CULTURAL TRANSLATION: THE CASE OF GEOGRAPHICAL INDICATION IN AGRIBUSINESS}

\section{LA ESTRATEGIA DE LA INTERNACIONALIZACIÓN DE NEGOCIOS EN LA PERSPECTIVA DE LA TRADUCCIÓN CULTURAL: EL CASO DE LA INDICACIÓN GEOGRÁFICA EN NEGOCIOS AGRÍCOLAS}

\author{
Simone de Lira Almeida \\ Doutora em Administração do Programa de Pós-Graduação em Administração da Universidade \\ Federal de Pernambuco - PROPAD/UFPE \\ Professora do Departamento de Hotelaria e Turismo da Universidade Federal de Pernambuco - \\ UFPE \\ Email: simoneufpe@ig.com.br (Brasil)

\section{Fernando Gomes de Paiva Júnior} \\ Doutor em Administração pela Universidade Federal de Minas Gerais - UFMG \\ Professor da Universidade Federal de Pernambuco - UFPE \\ Email: fernando.paivajr@ufpe.br (Brasil)

\section{José Roberto Ferreira Guerra} \\ Mestrando em Administração pelo Programa de Pós-Graduação em Administração da Universidade \\ Federal de Pernambuco - PROPAD/UFPE \\ Membro do Grupo de Estudos e Pesquisa em Inovação, Tecnologia e Consumo (GITEC) vinculado \\ ao Programa de Pós-Graduação em Administração da Universidade Federal de Pernambuco - \\ PROPAD/UFPE \\ Email: j.roberto.guerra@gmail.com (Brasil)
}


A Estratégia de Internacionalização de Negócios na Perspectiva da Tradução Cultural: O Caso da Indicação Geográfica no Agronegócio

\title{
A ESTRATÉGIA DE INTERNACIONALIZAÇÃO DE NEGÓCIOS NA PERSPECTIVA DA TRADUÇÃO CULTURAL: O CASO DA INDICAÇÃO GEOGRÁFICA NO AGRONEGÓCIO
}

\section{RESUMO}

A estratégia de internacionalização de negócios é contemplada na perspectiva da tradução cultural do queijo coalho produzido no agreste pernambucano, com alvo no processo de aquisição da Indicação Geográfica. A pesquisa documental com o suporte da análise temática de conteúdo auxiliou na investigação das comunicações institucionais do Serviço Brasileiro de Apoio as Micro e Pequenas Empresas (SEBRAE), que dizem respeito ao processo de certificação de origem para promoção do produto no mercado externo. As estratégias de tradução cultural adotadas pelos produtores de queijo se coadunam com a atuação em rede dos atores envolvidos na tarefa de certificação para a melhoria da qualidade e agregação de valor ao produto. A padronização e a adaptabilidade aos parâmetros dos órgãos reguladores do agronegócio contribuem para a adequação do produto a códigos culturais mundializados e sua comercialização na arena internacional.

Palavras-chave: Dimensão Cultural; Internacionalização de Negócios; Identidade Cultural.

\section{THE INTERNATIONALIZATION OF BUSINESS STRATEGY IN THE PERSPECTIVE OF CULTURAL TRANSLATION: THE CASE OF GEOGRAPHICAL INDICATION IN AGRIBUSINESS}

\begin{abstract}
The strategy of business internationalization is addressed from the perspective of the cultural translation of curd cheese produced in rural Pernambuco, with the objective of acquiring the status of Geographical Indication. With the support of thematic content analysis (TCA), the documented research helped in the investigation of the institutional communications of the Brazilian Service to Support Micro and Small Enterprises (SEBRAE), concerning the process of certification of origin (CO) for product promotion in foreign markets. Cultural translation strategies adopted by cheese producers are in keeping with the networking of those responsible for obtaining the certification that will improve the quality and value of the product. The standardization and adaptability of the parameters of the agribusiness regulators contribute to the suitability of the product to globalize cultural codes and its marketing in the international arena.
\end{abstract}

Keywords: Cultural Dimension; Business Internationalization Process; Cultural Identity.

Revista Ibero-Americana de Estratégia - RIAE, São Paulo, v. 9, n. 2, p. 75-98, mai./ago. 2010. 


\section{LA ESTRATEGIA DE LA INTERNACIONALIZACIÓN DE NEGOCIOS EN LA PERSPECTIVA DE LA TRADUCCIÓN CULTURAL: EL CASO DE LA INDICACIÓN GEOGRÁFICA EN NEGOCIOS AGRÍCOLAS}

\section{RESUMEN}

La estrategia de internacionalización de negocios es contemplada en la perspectiva de la traducción cultural del queso de cuajo producido en zonas rurales de Pernambuco, con el proceso de adquisición de la Indicación Geográfica. La investigación documental, con el soporte del análisis del contenido temático, ayudó en las investigaciones de las comunicaciones institucionales del Servicio Brasileño de Apoyo a las Micro y Pequeñas Empresas (SEBRAE), sobre el proceso de certificación de origen para la promoción del producto en el mercado externo. Las estrategias de traducción cultural adoptadas por los productores de queso están conforme la actuación de la red de los actores involucrados en la tarea de certificación para mejorar la calidad y darle mayor valor agregado al producto. La normalización y la capacidad de adaptación a los parámetros de los órganos reguladores del negocio agrícola contribuyen para la adecuación del producto a los códigos culturales globalizados y a su comercialización en el ámbito internacional.

Palabras-clave: Dimensión Cultural; Internacionalización de Empresas; Identidad Cultural. 
A Estratégia de Internacionalização de Negócios na Perspectiva da Tradução Cultural: O Caso da Indicação Geográfica no Agronegócio

\section{INTRODUÇÃO}

As rápidas e constantes mudanças ocorridas no mundo empresarial vêm provocando modificações estruturais nos mercados. A queda gradual das barreiras protecionistas entre países, aliada aos avanços tecnológicos e às mudanças institucionais, tem proporcionado complexa interconexão entre as diversas partes do mundo, de modo a encurtar as barreiras físicas e culturais entre povos e nações (Castells, 2007).

Em virtude da maior "proximidade", a competição está se acirrando e o escopo geográfico de atuação das organizações tende a se expandir graças ao aumento de economia e tecnologia globalizadas (Hitt, Ireland \& Hoskisson, 2001). Nesse aspecto, destaca-se o surgimento do conceito que Hisrich e Peters (2004) apresentam como "Economia Global Hipercompetitiva". Nela, empresas de pequeno, médio e grande porte que detinham um espaço competitivo próprio e dispunham de características marcantemente diferentes (Etmad \& Wright, 1999) - competem diretamente na busca por recursos em mercados amplamente interconectados, pois vislumbram oportunidades de ampliação do mercado e sofrem as consequências da entrada de novos competidores em sua área de abrangência, forçando-as a agirem e pensarem mais globalmente.

Os líderes das organizações empreendedoras que antes possuíam um escopo de atuação limitado pelas fronteiras locais e nacionais agora têm buscado oportunidades em mercados transnacionais. Com o advento do Empreendedorismo Internacional, o fenômeno da internacionalização de negócios continua sendo visto apenas como o processo de transposição das fronteiras nacionais, como se fosse um movimento meramente geográfico que se potencializa por meio da aquisição de conhecimentos, de modo a permitir a transnacionalização de empreendimentos.

A acirrada competição de mercado, juntamente com o crescente padrão de exigência dos consumidores em relação à qualidade, tem estimulado organizações a buscarem certificações para diferenciar produtos e serviços e, concomitantemente, propiciar confiança a seus consumidores. Independentemente do tipo de certificação, os selos obtidos por este processo garantem que o produto certificado atenda às especificações impostas pelo agente regulador (Lazzarotto, 1999).

No contexto do agronegócio, a procura por alimentos certificados cresce gradativamente. A desconfiança instituída após o episódio do mal da "vaca louca" na Comunidade Europeia fez com que a população se preocupasse em obter informações para melhorar o critério de escolha diante de situações de incerteza quanto à qualidade do produto e a segurança do consumidor.

Revista Ibero-Americana de Estratégia - RIAE, São Paulo, v. 9, n. 2, p. 75-98, mai./ago. 2010. 
Dessa forma, a intenção das empresas que aderem ao sistema de certificação consiste em dispor de subsídios capazes de instituir uma relação de confiança com o mercado (Altmann, 2005).

Um tipo de certificação que vem recebendo atenção não apenas de técnicos, gestores e acadêmicos, mas também de consumidores e organizações governamentais interessados no agronegócio são as Identificações Geográficas (IG). As Indicações Geográficas constituem-se um direito de propriedade intelectual, que difere de outras modalidades pelo seu caráter de direito coletivo. Isso significa que, diferentemente da marca ou patente, cujo direito de exclusividade é referida a um único ator, a proteção via Indicação Geográfica se direciona a uma coletividade (Gonçalves, 2007).

Este estudo parte do pressuposto de que a conquista de um novo mercado não deve ser compreendida apenas como uma simples transposição das fronteiras geográficas, uma vez que o entendimento da "lógica cultural e processual" do outro (i.e., do público-alvo) é um elemento fundamental à internacionalização. Por esse motivo, buscamos averiguar como ocorre a estratégia de internacionalização de negócios sob a perspectiva da lógica cultural no processo de aquisição da Indicação Geográfica do queijo coalho de Pernambuco. Para tanto, investigamos as ações do Serviço Brasileiro de Apoio às Micro e Pequenas Empresas (SEBRAE) com respeito à obtenção do registro de Indicação Geográfica do queijo coalho produzido no agreste pernambucano, ao pressupor que esse discurso institucional apresenta um conteúdo a partir do qual certos atributos culturais podem ser abstraídos (Johnson, 2006).

\section{AS ESTRATÉGIAS DE INTERNACIONALIZAÇÃO DE NEGÓCIOS}

O fenômeno da internacionalização das empresas começou a ser amplamente investigado na literatura de negócios internacionais por volta da segunda metade dos anos 1970 e início dos 1980, quando foram concebidas as primeiras modelagens que objetivavam explicar como um determinado empreendimento iniciava e expandia seu envolvimento com os mercados internacionais (Rocha, 2002).

Na literatura tradicional sobre internacionalização de empresas, é notório que grande parte dos estudos dedicou-se a compreender as peculiaridades de tal fenômeno por meio de grandes organizações (Etmad \& Wright, 1999). Essa exclusividade de enfoque, contudo, se justificava pelo fato de que - por muito tempo - essas peculiaridades têm dominado a "arena internacional".

Em um primeiro momento, os estudos de internacionalização estiveram relacionados ao "enfoque econômico". Nesse espectro, as abordagens sobre internacionalização examinavam tal 
A Estratégia de Internacionalização de Negócios na Perspectiva da Tradução Cultural: O Caso da Indicação Geográfica no Agronegócio

processo analisando as tendências macroeconômicas nacionais e internacionais com base em teorias de comércio, localização, balanço de pagamentos e taxa de câmbio. Dentre as principais teorias pertencentes a esse grupo, encontram-se a de Custos de Transação e a do Paradigma Eclético ou Teoria OLI ${ }^{\mathrm{i}}$.

Num segundo estágio, surge a visão que privilegia o enfoque organizacional, colocando o homem comportamental no lugar do econômico. Tal ponto de vista tem as raízes de seus pressupostos apoiadas no Modelo de Internacionalização da Escola de Uppsala (Johanson \& Vahlne, 1977) e, dada a sua grande difusão entre os teóricos organizacionais, será adotado o termo “visão tradicional" para se fazer menção ao pensamento ainda predominante no mundo organizacional.

O modelo de Uppsala investiga o fenômeno da internacionalização como um processo de etapas sequenciadas, desde formatos de internacionalização de baixo envolvimento, risco e investimento em recursos (e.g., exportação), até modos de internacionalizar-se em que o comprometimento da firma com tais variáveis é alto (e.g., internacionalização com subsidiárias). Assim, a preocupação dos teóricos de Uppsala dirigiu-se mais em descrever o processo de internacionalização dos negócios e as forças atuantes que propriamente em explicar as motivações que levam as empresas a investir no exterior, como no caso das teorias de enfoque econômico.

Johanson e Vahlne (1977) evidenciam a existência de três pressupostos nos quais se orienta o modelo de Upssala. Assim, os autores resumem que a falta de conhecimento é reconhecida como o maior obstáculo na internacionalização (i.e., distância psíquica ${ }^{i i}$ ), sendo o conhecimento adquirido por meio da experiência considerado único e indispensável à aprendizagem e, por fim, que a empresa se internacionaliza de maneira gradual. Nessa perspectiva, os reinvestimentos são constantes e o conhecimento adquirido "abre espaço" para a propagação de uma nova etapa. Os diversos modos de entrada, consequentemente, poderiam ser entendidos como um continuum de níveis crescentes de comprometimento de recursos, controle, exposição ao risco e potencial de lucros, desde o modo de exportação até o modo de subsidiária.

Como consequência da importância crescente dos novos formatos de organização (i.e., startups globals, high technology start-ups, international new ventures e born globals), um novo cenário sobrescreve-se ao primeiro e os esforços de compreensão rumam em direção e sentido ao esclarecimento da "nova realidade" (Moen, 2002). Para isso, no entanto, é indispensável o melhor entendimento acerca da dimensão cultural para superação da sequência determinista do modelo de Upssala.

Revista Ibero-Americana de Estratégia - RIAE, São Paulo, v. 9, n. 2, p. 75-98, mai./ago. 2010. 
Simone de Lira Almeida, Fernando Gomes de Paiva Júnior \& José Roberto Ferreira Guerra

\section{A INTERNACIONALIZAÇÃO DOS NEGÓCIOS SOB A PERSPECTIVA CULTURAL}

Nas últimas décadas, tornou-se possível observar uma aceleração no processo de integração econômica mundial. Nunca a abertura comercial e a difusão cultural entre os países foram tão intensas a ponto de formar elos capazes de permitir se relacionar mercados distantes por meio de características comuns. Em decorrência do deslocamento de fluxos econômico-culturais, a globalização tem se constituído em importante instrumento de homogeneização ao criar mercados locais heterogêneos, servindo o local com signos universais (Stiglitz, 2003; Bhagwati, 2004).

Em paralelo às forças dominantes de homogeneização cultural produzidas pela globalização contemporânea, cresce a valorização dos produtos tradicionais em defesa da identidade cultural dos povos. O temor à padronização dos costumes fortalece o sentimento de regionalismo que visa proteger uma identidade cultural ameaçada pela rapidez das interações mundiais. Sob esse ponto de vista, Burity (2000) afirma que, embora a globalização represente certa forma de interconexão e interpenetração entre regiões, estados nacionais e comunidades locais, ela também se faz acompanhar por uma potencialização da demanda, por singularidade e pelo espaço para a diferença e o localismo.

A tradição não deve ser entendida, por sua vez, como um cordão umbilical que inclui passado, presente e futuro numa linha ininterrupta. Na sociedade contemporânea, a ideia de núcleo imutável e atemporal associada à tradição torna-se um mito que tem o potencial de "moldar nossos imaginários, influenciar nossas ações, conferir significados às nossas cidades e dar sentido à nossa história" (Hall, 2006, p. 29).

Os elementos da tradição não possuem uma posição fixa ou determinada, nem significados que possam ser transportados no tempo de forma inalterável. O significado das formas culturais é marcado pela história e pelo contexto, de modo que não existe um significado estável desde sua origem. Seus elementos "podem ser reorganizados para se articular com diferentes práticas e posições e adquirir um novo significado e relevância” (Hall, 2006, p. 243).

Os acontecimentos que caracterizam a pós-modernidade vêm subvertendo a ideia tradicional de cultura como propriedade natural e autêntica de populações circunscritas a limites territoriais específicos. Ao mesmo tempo, as mudanças vivenciadas no âmbito tecnológico, econômico, social, político e cultural, a partir da segunda metade do século XX, nos impõem uma maneira diferenciada de pensar a cultura que se aproxime da dinamicidade da vida cotidiana.

A Teoria Cultural Contemporânea, inspirada pela formação discursiva dos Estudos Culturais (EC), empreende os deslocamentos teóricos em torno da temática cultural de modo a contribuir para a construção de um entendimento mais amplo desse conceito e de suas relações com as demais 
A Estratégia de Internacionalização de Negócios na Perspectiva da Tradução Cultural: O Caso da Indicação Geográfica no Agronegócio

esferas da sociedade. Dentro da perspectiva teórica dos EC, os esforços se direcionam para o entendimento da cultura não apenas como expressão artística ou domínio material, mas como processo de domínio simbólico, de produção de sentido, de construção de identidades (Veiga-Neto, 2000).

Os significados de um produto cultural são posicionais e relacionais, ou seja, não estão nos seus elementos tangíveis, mas no seu uso. Eles não são transportáveis de um espaço geográfico a outro sem sofrer modificações como algo acabado. As variações do significado acontecem durante o processo de tradução, segundo o qual, o produto de origem serve como fonte de criação de um novo produto. Esse "novo" não é completamente dissociado do primeiro, já que a cultura nunca deixa de transparecer nos produtos transformados (Henry \& Walker, 1994). Pode-se dizer, então, que existe uma diferenciação estratégica entre os produtos culturais, mas não uma separação (Hall, 2006). A Figura 1 ilustra esse processo de tradução cultural por meio do qual os significados culturais de determinado produto podem ser recriados para que haja possibilidade de diálogo entre significados oriundos de um lugar de cultura com os padrões da cultura de destino.

Figura 1 - Tradução do artefato cultural no processo de internacionalização.

\begin{tabular}{||c|c|c|c|}
\hline $\begin{array}{c}\text { Produto Cultural } \\
\text { Significados do produto } \\
\text { na cultura de origem }\end{array}$ & $\rightarrow \begin{array}{c}\text { Estratégia de Tradução } \\
\text { Adaptação da lógica cultural } \\
\text { do destino }\end{array}$ & $\rightarrow \begin{array}{c}\text { "Novo" Produto Cultural } \\
\text { Absorção dos padrões } \\
\text { culturais de destino }\end{array}$ \\
\cline { 3 - 4 }
\end{tabular}

Fonte: Elaborado pelos autores, 2009.

O processo de hibridização faz com que o sistema cultural de uma localidade passe a ser compreendido como um mosaico de locais de cultura; assim a ideia de pertencimento social, que estrutura a visão antropológica de cultura cai em desuso, posto que a cultura está crescentemente se “desterritorializando" (Bhabha, 2001). Em decorrência disso, diminui a distância psíquica entre os povos, uma vez que determinado local de cultura é influenciado por fragmentos de outros locais (Child, NG \& Wong, 2002). A rediscussão dessa distância facilita o transnacionalizar-se ao "minimizar" as barreiras clássicas da literatura de internacionalização de negócios, bem como ao se "equalizar" o sistema de comunicação entre os diversos locais de cultura (cf. Moen \& Servais, 2002).

Revista Ibero-Americana de Estratégia - RIAE, São Paulo, v. 9, n. 2, p. 75-98, mai./ago. 2010. 
Simone de Lira Almeida, Fernando Gomes de Paiva Júnior \& José Roberto Ferreira Guerra

\section{INDICAÇÃO GEOGRÁFICA: ALINHAMENTO ENTRE CULTURA LOCAL E GLOBAL}

No Brasil as IG são reguladas pela Lei de Propriedade Industrial (Lei nº. 9.279, de 14 de maio de 1996) e no âmbito internacional são reconhecidas pelo Acordo sobre Aspectos dos Direitos de Propriedade Intelectual Relacionados ao Comércio (ADPIC), em inglês, Trade Related Aspects of Intellectual Property Rights (TRIPS) da Organização Mundial do Comércio (OMC).

O texto legislativo brasileiro não define o que é Indicação Geográfica, apenas assinala de que se constitui. Conforme o art. 176 da Lei $\mathrm{n}^{\mathrm{o}}$. 9.279, "constitui-se indicação geográfica a Indicação de Procedência ou a Denominação de Origem" (Lei nº 9.279, 1996). No entanto, a definição das duas espécies de proteção para produtos e serviços agropecuários é encontrada, respectivamente, nos artigos 177 e 178 da referida lei:

- Indicação de Procedência (IP): “nome geográfico de país, cidade, região ou localidade de seu território, que se tenha tornado conhecido como centro de extração, produção ou fabricação de determinado produto ou de prestação de determinado serviço" (Lei $\left.\mathrm{n}^{\mathrm{o}} .9 .279,1996\right)$.

- Denominação de Origem (DO): "nome geográfico de país, cidade, região ou localidade de seu território, que designe o produto ou serviço cujas qualidades ou características se devam exclusiva ou essencialmente ao meio geográfico, incluídos fatores naturais e humanos" (Lei n. 9.279, 1996).

Embora a designação do "nome geográfico"iii seja um aspecto comum às duas espécies de IG - ou seja, não se pode qualificar como indicação geográfica uma indicação ou denominação que não aponte um lugar ou um espaço geográfico determinado - do ponto de vista funcional, existe diferença entre a IP e a DO.

A Indicação de Procedência é atribuída à região ou localidade que adquiriu fama por causa de seus produtos ou serviços. Nessa modalidade de IG, o centro de extração, produção ou fabricação é indicado, mas não são realçadas as qualidades ou características únicas de um produto ou serviço vinculadas com o meio geográfico.

Por outro lado, a Denominação de Origem tem por obrigação destacar qualidades ou características de um produto ou serviço, que se devem essencialmente ao meio geográfico. Isso significa que para as DO não basta o estabelecimento no local designado, mas também a comprovação de que os fatores naturais (clima, solo, temperatura, água, fauna, flora) e humanos 
A Estratégia de Internacionalização de Negócios na Perspectiva da Tradução Cultural: O Caso da Indicação Geográfica no Agronegócio

(práticas e técnicas típicas empregadas pelos moradores do lugar e da região) atribuem uma característica ímpar ao produto.

Até o momento, existem três Indicações de Procedência reconhecidas no Brasil pelo Instituto Nacional de Propriedade Industrial (INPI), além do caso da cachaça, que foi regulamentado por Decreto: a IP "Vale dos Vinhedos" para vinhos tintos, brancos e espumantes; a IP "Região do Cerrado Mineiro" para o produto café e a IP "Pampa Gaúcho da Campanha Meridional" para o produto carne bovina e seus derivados. Em relação ao registro de denominação de origem, ainda não há casos no Brasil tendo em vista a atual inexistência de instituições credenciadas para auferir a qualidade singular dos produtos (Gurgel, 2006).

A qualidade conferida aos produtos certificados é um atributo de valor compreendido mundialmente pela sociedade contemporânea, o que facilita o acesso da mercadoria a novos mercados. No caso da Indicação Geográfica, acredita-se que a certificação também possa ajudar a diferenciar alimentos produzidos por agricultores familiares que não podem ser competitivos pela produção em larga escala (Lea, Lagares \& Braga, 2005).

A Denominação de Origem, em particular, reflete o desenvolvimento de uma agricultura que valoriza as tradições e os modos de fazer diferenciados de um território (Altmann, 2005; Lea et al., 2005). Contudo, isso não significa que a identidade cultural atrelada ao produto tenha um caráter estático. Nesse sentido, o reconhecimento do processo de mundialização das culturas não nos permitiria ver a identidade cultural como uma entidade fixa e desconectada de outros contextos (Silva, 2000; Hall, 2006; Ortiz, 2007).

No âmbito da mundialização, a riqueza das manifestações culturais específicas a certos povos tende a se tornar supérflua e, consequentemente, ignorada. Dessa maneira, os produtos precisam adquirir signos e referências culturais que fogem aos limites territoriais para serem aceitos fora de seu local de origem (Ortiz, 2007). Curiosamente, a denominação de origem também parece incidir no produto para desterritorializar a cultura ao atribuir-lhe códigos desenraizados ${ }^{\mathrm{iv}}$. Na medida em que os produtos certificados adquirem referências culturais externas a seus limites territoriais para poder acessar novos mercados - serem exportados, por exemplo - fica difícil estabelecer fronteiras culturais rígidas que possam demarcar a origem do produto (Ortiz, 2007).

As Indicações Geográficas nos ajudam a desmistificar a noção de uma cultura autêntica quando esta integra signos locais a referências culturais globalmente reconhecidas no processo de certificação. Assim, a identidade cultural do produto é constituída no processo de certificação por meio de mesclas interculturais que não correspondem a nenhuma das identidades originais, embora contenha traços delas (Silva, 2000; Hall, 2006; Canclini, 2003).

Revista Ibero-Americana de Estratégia - RIAE, São Paulo, v. 9, n. 2, p. 75-98, mai./ago. 2010. 
As mudanças associadas ao produto em função da obtenção da Indicação Geográfica não se limitam aos atributos tangíveis. Se a introdução de critérios de certificação provoca mudanças na dimensão material do produto, elas repercutirão também na dimensão simbólica desse produto, uma vez que essas duas dimensões são indissociáveis (Bakhtin, 1999).

O significado de um produto cultural, a exemplo do queijo coalho, não está no objeto, nem sua atribuição ocorre no momento da produção. Em outros termos, a mercadoria não tem significado em si mesma. Seu significado, ou melhor, os significados, são frutos de processos distintos - representação, identidade, produção, consumo e regulação - que se conectam para atribuir significados provisórios a esse artefato cultural (Du Gay et al., 1997).

\section{PROCEDIMENTOS METODOLÓGICOS}

Este estudo, de natureza exploratória, adotou a pesquisa documental como estratégia de investigação. A coleta de documentos se direcionou ao discurso de um parceiro institucional estratégico no projeto de Indicação Geográfica do queijo coalho pernambucano: o SEBRAE.

A escolha dos textos do SEBRAE se deve ao fato de que essa instituição vem estimulando os produtores do Agreste de Pernambuco a obterem o registro de Indicação Geográfica desde 2004, quando a instituição promoveu uma missão internacional a região de Auvergne, no centro da França. Na ocasião, 8 produtores e 7 técnicos institucionais visitaram fazendas francesas que possuem forte tradição na produção de queijos. Como resultado da viagem houve a criação de um plano de trabalho, formulado pelos produtores, denominado Carta de Auvergne. Atualmente o SEBRAE vem fornecendo orientação técnica aos produtores de queijo do Agreste de Pernambuco para criação da associação de certificação e melhoria do processo produtivo.

O corpus de análise constituiu-se de todas as matérias publicadas sobre a Certificação do queijo coalho em jornais e revistas institucionais do SEBRAE nos anos de 2006 e 2007. Nesse percurso, identificamos uma matéria publicada na Agência SEBRAE de Notícias no dia 20/5/2006 e outra no dia 05/9/2007, além de uma reportagem durante o mês de outubro de 2007 publicada na Revista SEBRAE Agronegócios.

A confiabilidade da informação foi avaliada a partir das variáveis: credibilidade da fonte e credibilidade do conteúdo. Essas duas variáveis influenciam-se mutuamente; ou seja, fontes confiáveis são entendidas como desenvolvedoras de conteúdo confiáveis, e conteúdos confiáveis são entendidos como originados por fontes confiáveis (Slater \& Rouner, 1996). Com base no princípio de influência mútua das variáveis de confiabilidade e nas sugestões apontadas por Paim, 
A Estratégia de Internacionalização de Negócios na Perspectiva da Tradução Cultural: O Caso da Indicação Geográfica no Agronegócio

Nehmy e Guimarães (1996), consideramos o prestígio, o respeito e a reputação do SEBRAE para atribuir credibilidade, tanto no que diz respeito à fonte quanto ao conteúdo de seus textos.

O tratamento dos dados está no bojo da abordagem qualitativa de cunho interpretativo (Minayo, 2000; Merriam, 1998) e constitui-se da análise de conteúdo temática. Operacionalmente, a análise qualitativa de conteúdo se deu em três fases orientadas pelo procedimento de análise desenvolvido por Campos (2004). A primeira etapa consistiu na leitura flutuante dos textos selecionados, com o intuito de apreender e organizar de forma não estruturada aspectos importantes para as próximas fases da análise. $\mathrm{Na}$ segunda etapa, definiu-se o tema como unidade de análise. $\mathrm{Na}$ terceira etapa, realizou-se o processo de categorização não apriorística para efetiva análise do material. Nesse caso as categorias emergiram totalmente do contexto do texto, o que exigiu do pesquisador um intenso ir e vir ao material analisado e às teorias embasadoras para não perder de vista o atendimento aos objetivos da pesquisa. As categorias de análise foram, então, agrupadas em torno dos três momentos do processo de tradução cultural apresentados na Figura 1 para destacar as estratégias que estão sendo desenvolvidas para inserção do queijo coalho no mercado internacional.

\section{A PRODUÇÃO DE QUEIJO COALHO COMO OBJETO DE ESTUDO}

O queijo coalho é um produto típico da Região Nordeste do Brasil fabricado principalmente nos Estados de Pernambuco, Ceará, Rio Grande do Norte e Paraíba. Nesses Estados, o queijo coalho se destaca entre os principais tipos de queijos artesanais de fabricação e consumo comprovadamente incorporados à cultura regional de tradição secular, transferida de geração em geração. É um produto extensamente apreciado pelo nordestino quer seja assado na brasa, quer seja frito, embora também esteja ganhando novos consumidores na Região Sudeste por causa de seu sabor peculiar e principalmente sua maneira de consumo (Morais, 1995; Munck, 2004).

Sua produção representa uma atividade bastante significativa para a economia regional, visto que em determinadas localidades é a principal fonte de renda e sobrevivência da população. No Estado de Pernambuco, especificamente, a produção de leite e derivados constitui um dos principais suportes econômicos nas microrregiões do Vale do Ipojuca, Vale do Ipanema e Garanhuns, além de uma importância relativa na Zona da Mata, Sertão do São Francisco, Sertão do Araripe e Sertão do Pajeú. Estes fatos demonstram a relevância econômica e social da produção de queijo para o Estado Pernambucano, especialmente no que diz respeito aos pequenos produtores do Agreste e Sertão (Almeida, Paiva \& Guerra, 2009).

Revista Ibero-Americana de Estratégia - RIAE, São Paulo, v. 9, n. 2, p. 75-98, mai./ago. 2010. 
Apesar de ser produzido há mais de 150 anos em vários Estados da Região Nordeste, o queijo coalho é fabricado artesanalmente em pequenas fazendas rurais ou em pequenas queijarias urbanas ou rurais. Segundo Duarte (1999), alimentos obtidos por processos artesanais têm grande possibilidade de se apresentarem contaminados, por causa do uso de matérias-primas de fontes não seguras e da falta de higiene pessoal e ambiental no processamento, além do armazenamento e transporte inadequados do produto. Diante dessa realidade, diversos trabalhos científicos defendem a introdução de melhorias na técnica de fabricação de queijos caseiros para se atingir produtos de qualidade que protejam a saúde do consumidor (Cavalcante et al, 2007; Duarte, 1999; Morais, 1995).

Originalmente o queijo coalho é produzido a partir do leite $\mathrm{cru}^{\mathrm{v}}$, coagulado pela ação do coalho animal $^{\mathrm{vi}}$ (Valença, 2005). Em termos de cultura local, o consumidor tem o hábito de experimentar o produto in natura no momento da compra para atestar a quantidade de sal, pois não há padronização do produto.

Em virtude das especificidades do queijo coalho, vários Estados do Nordeste criaram uma Legislação própria para este produto (Munck, 2004). Em Pernambuco, tramita na Assembleia Legislativa do Estado um projeto de lei que estabelece as exigências do processo de produção do queijo artesanal de acordo com a capacidade de produção, partindo-se do princípio de que as atuais exigências sanitárias para comercialização do queijo são inalcançáveis pelos pequenos produtores.

Em termos nacionais, o Regulamento Técnico de Identidade e Qualidade de Produtos Lácteos estabelece os requisitos mínimos de qualidade que deverão ser cumpridos para que o queijo coalho possa ser destinado ao consumo humano. Esse Regulamento define o produto como "o queijo que se obtém por coagulação do leite por meio de coalho ou outras enzimas coagulantes apropriadas, complementada ou não pela ação de bactérias lácteas selecionadas e comercializado normalmente com até 10 (dez) dias de fabricação" (Munck, 2004)."

\section{ANÁLISE DOS RESULTADOS}

O queijo coalho é reconhecido não apenas como um alimento, mas, sobretudo, como manifestação da cultura pernambucana. Conforme os documentos do SEBRAE, o registro de Indicação Geográfica consiste numa estratégia para a construção da identidade do queijo produzido no Agreste Pernambucano, segundo ilustra a seguinte citação: “A certificação dará ao queijo ali produzido uma identidade própria, que o distinguirá dos demais produtos de igual natureza disponíveis no mercado" (SEBRAE, 2007a, p. 16). O advérbio de lugar "ali” indica o espaço 
A Estratégia de Internacionalização de Negócios na Perspectiva da Tradução Cultural: O Caso da Indicação Geográfica no Agronegócio

geográfico que será beneficiado com o projeto, enquanto o adjetivo "própria" sugere o caráter exclusivo do produto em relação aos queijos produzidos em outras localidades. Implicitamente, atribui-se qualidade aos produtos locais, como uma representação de poder, competência e prestígio.

A noção tradicional de identidade evidencia a crença de um produto autocontido na localidade, como se esse fosse desvinculado de processos de hibridação ${ }^{\text {vii }}$ cultural. Essa delimitação identitária não diz respeito apenas a limites territoriais, mas se reveste de um valor simbólico inerente aos atributos intangíveis do produto (Canclini, 2003). Muitas vezes, a valorização de uma região pode ser entendida como uma estratégia de proteção do ator local.

Contudo, o reconhecimento do cruzamento de fronteiras, da indefinição e da ambiguidade da identidade nos possibilita ver o caráter "artificialmente" imposto das identidades fixas. O processo de hibridação dissolve a ingênua noção de pureza cultural diante do intercâmbio dos grupos que se reúnem sob as diferentes identidades nacionais, raciais ou étnicas. A identidade constituída por meio dessa hibridação não corresponde completamente às identidades originais, embora contenha traços delas. As culturas têm seus 'locais', no entanto, não é tão fácil identificar de onde elas se originam (Silva, 2000; Hall, 2006).

Outra reportagem institucional do SEBRAE aponta que:

O termo de Indicação Geográfica (IG) passou a ser utilizado quando produtores, comerciantes e consumidores começaram a perceber que alguns produtos, de determinados lugares, apresentavam qualidades particulares atribuídas à sua origem geográfica (SEBRAE, 2007a, p. 16).

A palavra "qualidade" é empregada no sentido de "características" para destacar, mais uma vez, o caráter de exclusividade encontrado nos produtos que possuem Indicação Geográfica. Assim, pressupõe-se que a IG destaca as manifestações culturais, específicas de um povo na medida em que a particularidade do produto está ligada a determinado território.

A genuinidade local, expressa em produtos ou serviços identificados com Indicação Geográfica possibilita o surgimento de novas formas de relação com consumidores. Garantir o reconhecimento da origem e da qualidade de produtos agropecuários por meio da Indicação Geográfica pode ser a forma de assegurar a reputação e a diferenciação da mercadoria no momento em que o controle sanitário rigoroso, a rastreabilidade do processo produtivo e a promoção de produtos de qualidade diferenciada passam a se constituir critérios de negociação internacional (Altmann, 2005). No caso do queijo coalho, espera-se que a etiqueta da IG crie no

Revista Ibero-Americana de Estratégia - RIAE, São Paulo, v. 9, n. 2, p. 75-98, mai./ago. 2010. 
consumidor a confiança de adquirir um alimento seguro para sua saúde, graças à qualidade promovida pela Associação de Certificação.

O INPI estabelece o associativismo como regra para o exercício do direito ao uso exclusivo do nome geográfico (http://www.inpi.gov.br), por isso o esforço para garantir a certificação do queijo coalho demandou a criação da Associação de Certificação do Queijo Coalho da Região do Agreste de Pernambuco (ACQP). Os produtores, que anteriormente trabalhavam de forma individualizada, foram estimulados e orientados pelo SEBRAE a se reunirem não apenas com outros produtores de queijo, mas também com fornecedores de leite a fim de garantir a qualidade em toda cadeia produtiva. Para desenvolver esse trabalho, a Associação vem recebendo assessoria técnica de parceiros locais para atender aos padrões dos órgãos reguladores. A rede formada em torno do projeto de certificação pode ser visualizada no Quadro 1.

\begin{tabular}{|l|l|}
\hline \multicolumn{1}{|c|}{ Parceiros Estratégicos } & \multicolumn{1}{c|}{ Atribuiçães } \\
\hline $\begin{array}{l}\text { ACQP - Associação de Certificação } \\
\text { do Queijo Coalho da Região do } \\
\text { Agreste de Pernambuco }\end{array}$ & $\begin{array}{l}\text { - Definir regulamento técnico } \\
\text { - Acompanhar os padrões instituídos } \\
\text { - Avaliar a qualidade do leite e do queijoproduzidos pelos } \\
\text { associados. }\end{array}$ \\
\hline $\begin{array}{l}\text { ITEP - Instituto de Tecnologia de } \\
\text { Pernambuco }\end{array}$ & $\begin{array}{l}\text { - Definir e formalizar a Área Geográfica de produção de queijo de } \\
\text { coalho no Agreste de PE } \\
\text { - Promover aprimoramento tecnológico dos produtores de leite de } \\
\text { PE }\end{array}$ \\
\hline $\begin{array}{l}\text { SEBRAE - Serv iço Brasileiro de } \\
\text { Apoio às Micro e Pequenas Empresas }\end{array}$ & $\begin{array}{l}\text { - Estimular o associativismo } \\
\text {-Fornecer orientaçãotécnica aos produtores de queijopara criação } \\
\text { da associação e melhoria do processo produtivo }\end{array}$ \\
\hline $\begin{array}{l}\text { INPI - Instituto Nacional da } \\
\text { Propriedade Industrial }\end{array}$ & $\begin{array}{l}\text { - Analisar projeto da ACQP para conceder Indicação Geográfica } \\
\text { aos produtores de queijo e leite do Agreste de PE. }\end{array}$ \\
\hline $\begin{array}{l}\text { ADAGRO - Agência de Defesa e } \\
\text { Fiscalização Agropecuária de } \\
\text { Pernambuco }\end{array}$ & $\begin{array}{l}\text { - Registrar, inspecionar e fiscalizar empresas que manipulem, } \\
\text { produzam, armazenem transportem ou comercializem produtos e } \\
\text { derivados agropecuários. }\end{array}$ \\
\hline
\end{tabular}

Quadro 1 - Rede de Parceiros Estratégicos para a Indicação Geográfica.

Fonte: Pesquisa direta, 2009.

Os produtos que conseguem obter o registro de Indicação Geográfica são reconhecidos com facilidade no mercado internacional, principalmente no momento em que as Indicações Geográficas estão se multiplicando e se expandindo em escala mundial, em razão do seu reconhecimento como direito de propriedade intelectual no marco da Organização Mundial do Comércio (Petithuguenin, 2006). Mais que isso, a IG reflete o desenvolvimento de uma nova ruralidade que ressignifica os produtos da agricultura familiar ao serem valorizadas as tradições e os 
A Estratégia de Internacionalização de Negócios na Perspectiva da Tradução Cultural: O Caso da Indicação Geográfica no Agronegócio

modos de fazer diferenciados de um território. Não obstante, o mundo rural se configura como um valor para o desenvolvimento social, contradizendo teorias que entendem a ruralidade como etapa a ser ultrapassada para o avanço do progresso e da urbanização (Lea, Lagares \& Braga, 2005; Dullius et al, 2008).

Outra passagem do texto do SEBRAE destaca elementos externos à localidade onde as identificações geográficas são tratadas como códigos internacionalmente reconhecidos. Primeiramente, cita-se que "hoje a terminologia (IG) é institucionalizada e, assim, conhecida mundialmente" (SEBRAE, 2007a, p. 16). Implicitamente, isso demonstra que o reconhecimento internacional do termo "Indicação Geográfica" pode servir como estratégia para se projetar o produto local no mercado global.

Em razão do registro de IG, existe a expectativa de aumento nas vendas do produto, tanto em território nacional como internacional. Essa intenção é desvelada pelo gestor do projeto de Desenvolvimento da Cadeia Produtiva do Leite, quando afirma que Pernambuco vende mais leite que derivados para outros estados. Com a certificação do queijo coalho, esse quadro poderá mudar, uma vez que o forte da exportação consistirá nos produtos de valor agregado (SEBRAE, 2007b).

A ação de "exportar", relacionada à existência de produtos com "valor agregado", sugere que o queijo coalho precisa adquirir novas características para se tornar valorizado no mercado externo. Esse argumento é reforçado pelo gestor do Projeto de Leite e Derivados ao afirmar que "Para isso, já estamos no caminho da padronização do queijo coalho" (SEBRAE, 2007a, p. 16). Dessa forma, verifica-se que o SEBRAE entende a entrada do queijo coalho em arenas comerciais nacionais e internacionais condicionada ao processo de padronização da mercadoria.

A ideia de autenticidade da cultura local se revela limitada, na medida em que o projeto de leite e derivados prevê "a padronização de cor, sabor e tamanho do produto" (SEBRAE, 2007a, p. 17). Se uma das características da cultura local é degustar o queijo no ponto de venda para atestar a quantidade de sal desejada antes da compra, dificilmente outras culturas aceitariam receber um queijo com sabor e aspecto diferente a cada compra, como tradicionalmente acontece no Nordeste do Brasil.

O conceito de que elementos específicos, nacionais ou regionais, são rebaixados à categoria de localismo nas trocas internacionais está levando o SEBRAE e seus parceiros a desenvolverem estratégias de incorporação de signos e referências culturais reconhecidos mundialmente ao produto. Isso implica uma desterritorialização do queijo como artefato cultural e das suas referências locais. No entanto, isso não que dizer que a cultura local tenha sido extinta, mas há de ser encontrada em outros lugares, pois, conforme sugere Canclini (2003, p. 218), “o problema não

Revista Ibero-Americana de Estratégia - RIAE, São Paulo, v. 9, n. 2, p. 75-98, mai./ago. 2010. 
se reduz, então, a conservar e resgatar tradições supostamente inalteradas. Trata-se de perguntar como estão se transformando, como interagem com as forças da modernidade."

Para a obtenção do registro de Indicação Geográfica, o produto local sofrerá adaptações no sentido de tornar-se culturalmente mais abrangente e universalmente aceito. Isso acontece porque o mercado internacional encerra disponibilidades estéticas nas quais os gostos se encontram predeterminados. A lógica contemporânea de negócio ocupa o lugar da tradição como fonte de legitimação da mercadoria, pois é ela que tem a capacidade de abarcar todo o planeta ao expressar um movimento socioeconômico que perpassa povos e nações. Logo, a riqueza das manifestações culturais, específicas a certos povos, torna-se supérflua, sendo por isso ignorada (Ortiz, 2007).

O gestor responsável pelo projeto de leite e derivados do SEBRAE-PE acrescenta que os produtores estão sendo orientados pelo francês Benoit Paquereau, consultor técnico em laticínios (SEBRAE, 2007a). Nesse trecho do discurso do SEBRAE, o emprego da palavra "orientados" serve para mostrar que os produtores necessitam de uma liderança técnica com conhecimento estrangeiro que lhe apontem os rumos de ação estratégica para garantir a conformidade do produto junto aos públicos nacionais e internacionais.

O contato com a cultura francesa, seja por meio do consultor, seja por meio das visitas realizadas a queijarias da França, levou os produtores locais a resgatarem a ideia de produção tradicional do queijo coalho. Eles estavam produzindo o queijo a partir do leite pasteurizado, no entanto uma das orientações de Benoit reside em fabricar o queijo a partir do leite cru, como são produzidos os queijos na Europa (SEBRAE, 2007a).

Do ponto de vista institucional, organizações que reproduzem práticas ditas "de classe mundial", batizando-se com essas fontes de vanguarda sob o pretexto de adquirir competitividade internacional frequentemente utilizam-se desse recurso para obter reputação (DiMaggio \& Powell, 1983).

Um dos textos é finalizado com o depoimento do engenheiro agrônomo e produtor de leite e queijo coalho, que volta a ressaltar que "esse certificado mostra que o produto traz características do local de origem" (SEBRAE, 2007a, p. 17). Contudo, as interações entre atores locais e estrangeiros que estão ocorrendo nesses processos parecem esfumaçar as fronteiras territoriais, assim como a autonomia das tradições locais. Isso gera uma hibridação sociocultural, na qual estruturas ou práticas discretas, que existiam de forma separada, combinam-se para gerar novas estruturas, objetos e práticas (Canclini, 2003, p. 19).

Os temas emergentes da análise de conteúdo foram organizados de forma a compor o diagrama do processo de tradução cultural apresentado na seção de revisão de literatura. A Figura 2 
A Estratégia de Internacionalização de Negócios na Perspectiva da Tradução Cultural: O Caso da Indicação Geográfica no Agronegócio

ilustra as principais estratégias de tradução cultural empregadas pelos produtores de queijo juntamente com seus parceiros para certificação de Indicação Geográfica do produto.

Figura 2 - Estratégias de Tradução Cultural dos Produtores de Queijo Coalho.

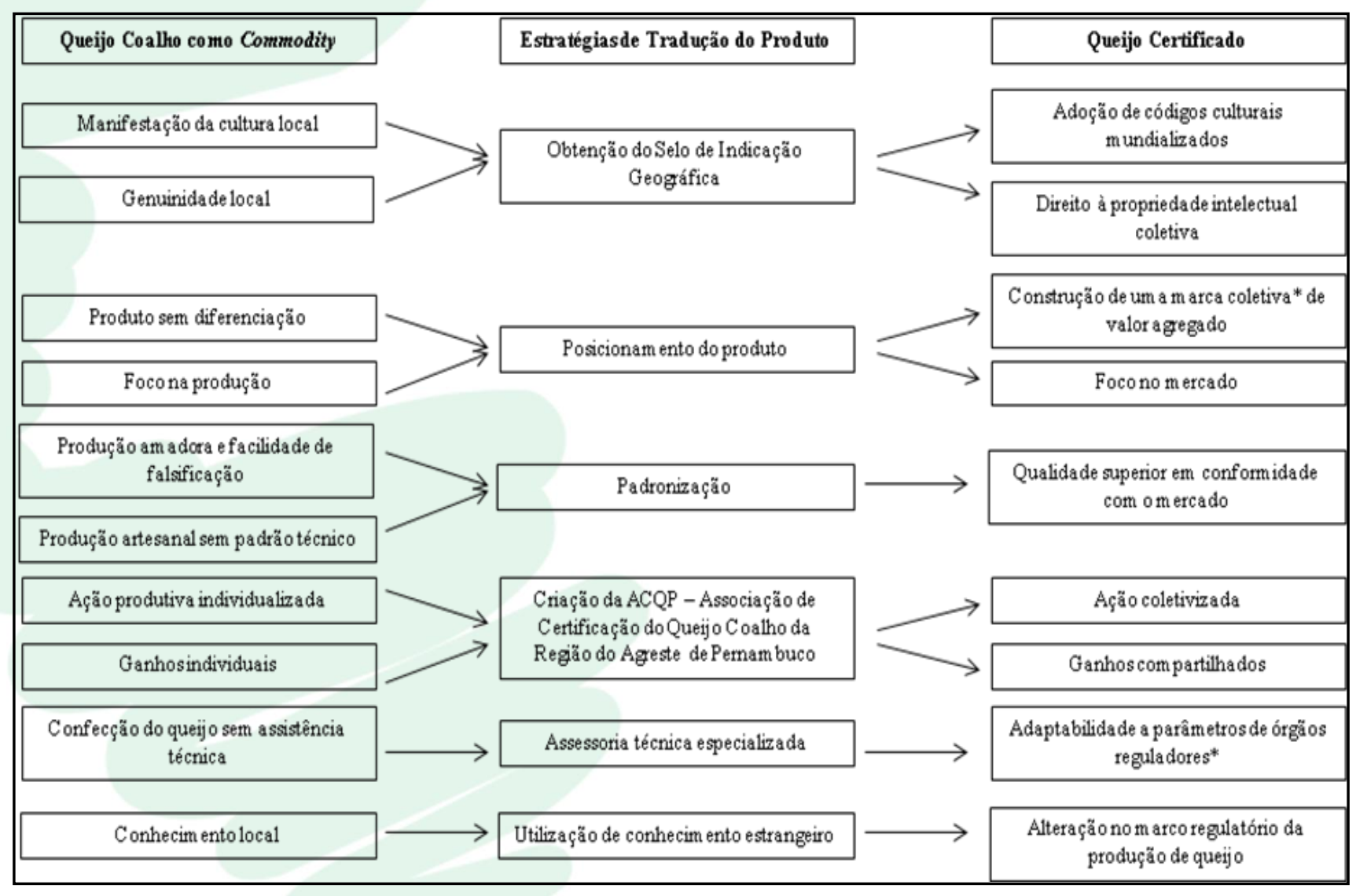

Fonte: Pesquisa direta, 2009.

\section{CONSIDERAÇÕES FINAIS}

Retornando à discussão inicial sobre a relevância da dimensão cultural no processo de internacionalização de negócios, de modo a contribuir para a competitividade das pequenas empresas no cenário internacional, chegamos a algumas considerações, cuja implicação estratégica de internacionalização advém do esforço de tradução do queijo no âmbito do processo de certificação.

A visão cultural do Empreendedorismo Internacional extrapola a dimensão geográfica, e a compreensão da lógica cultural do outro (i.e., o público) já não é compreendida apenas como meio

Revista Ibero-Americana de Estratégia - RIAE, São Paulo, v. 9, n. 2, p. 75-98, mai./ago. 2010. 
para a transposição dos "limites geográficos de um país", senão como a essência do termo internacionalizar-se. Portanto, a internacionalização estaria mais na compreensão e absorção da lógica cultural que propriamente no transcender de fronteiras.

Nesse sentido, a internacionalização pode ser concebida como um processo de "tradução" que possibilita a melhor sintonia entre os entes do negócio. A análise dos textos produzidos pelo SEBRAE revela que a Indicação Geográfica é uma estratégia de valorização da cultura local, a qual adquire também a lógica cultural de outros territórios. Assim, a tradição não é tratada como um elemento estático que pode ser transportado de um lugar a outro sem sofrer modificações, a considerar que a compreensão da cultura de destino seria uma exigência fundamental para aceitação do produto em novos mercados.

Por meio da ótica cultural, novos caminhos se abrem para o entendimento das dificuldades enfrentadas por determinadas organizações no sentido de serem reconhecidas pelo novo público e transgredirem os limites territoriais. Nesse contexto, mesmo que vencidas as limitações geográficas, a não adequação dos produtos ou serviços a necessidades, gostos e estilo da cultura do player internacional poderia significar o fracasso da tentativa de fixação no mercado externo.

A proposta cultural abre um parêntese em relação à relevância requerida pelos aspectos da cultura dos parceiros no processo de internacionalização de produtos. Em síntese, a atividade empreendedora de penetração em novos mercados poderia ocorrer sem que houvesse o deslocamento do processo produtivo entre mercados distintos, bastando para isso a incorporação da lógica cultural do público a ser atingido e, em seguida, a interação.

\section{IMPLICAÇÕES GERENCIAIS}

A atuação coletiva, a busca por conhecimento especializado, a adequação do processo produtivo aos padrões do mercado, juntamente com o estabelecimento de parcerias estratégicas, representam ações relevantes para o registro de Indicação Geográfica e comercialização do queijo coalho no mercado externo.

É imperativa a criação e consolidação de políticas públicas voltadas para o desenvolvimento de economias regionais que contribuem com a criação de redes de negócios voltadas para o processo de internacionalização de produtos locais.

O processo de Indicação Geográfica depende da mudança de atitude e do desenvolvimento de competências de gestão dos produtores locais e da potencialização de um sistema integrado de apoio à produção, à distribuição e ao consumo de um produto que pretende manter suas 
A Estratégia de Internacionalização de Negócios na Perspectiva da Tradução Cultural: O Caso da Indicação Geográfica no Agronegócio

características tradicionais e, ao mesmo tempo, dialogar com padrões mercadológicos internacionais. Nesse sentido, as estratégias de tradução cultural apontadas na análise deste estudo podem inspirar a aceleração e a viabilização da entrada de outros produtos tradicionais brasileiros na arena de negócios do mercado global.

* AGRADECIMENTO: Os autores agradecem ao CNPq e à CAPES pelo apoio concedido na realização deste estudo.

\section{REFERÊNCIAS}

Almeida, S. L., Paiva, F. G., Jr. \& Guerra, J. R. F. (2009). Identidade Cultural e Desenvolvimento Territorial: um olhar sobre as iniciativas para certificação de origem do queijo coalho em Pernambuco. In Aguiar, S. M. B. (org.) Gestão Pública: práticas e desafios (Vol. 2). Recife, Bagaço.

Altmann, R. (2005). Certificação de qualidade e origem e desenvolvimento rural - novo paradigma no mercado de alimentos. In Lea, L., Lages, V. \& Braga, C. (orgs.). Valorização de produtos com diferencial de qualidade e identidade: indicação geográfica e certificações para competitividade nos negócios. Brasília: SEBRAE.

Bakhtin, M. (1999). Marxismo e filosofia da linguagem: problemas fundamentais do método sociológico na ciência da linguagem. São Paulo: Hucitec.

Bhabha, H. K. (2001). O local da cultura. Belo Horizonte: Editora UFMG.

Bhagwati, J. (2004). In defense of globalization. Nova York: Oxford University Press.

Burity, J. A. (2000). Identidade e múltiplo pertencimento nas práticas associativas locais (Relatório de Pesquisa/2003). Recife, Fundação Joaquim Nabuco.

Campos, C. J. G. (2004). Método de análise de conteúdo: ferramenta para a análise de dados qualitativos no campo da saúde. Revista Brasileira de Enfermagem. 57 (5), 611-614. http://dx.doi.org/10.1590/S0034-71672004000500019

Canclini, N. G. (2003). Culturas Híbridas: estratégias para entrar e sair da modernidade. São Paulo: Editora da USP. 
Castells, M. (2007). A sociedade em rede. 10. ed. (Ed. ver.). São Paulo: Paz e Terra.

Cavalcante, J. F. M., Andrade, N. J., Furtado, M. M., Ferreira, C. L. L. F., Pinto, C. L. O. \& Elard, E. (2007). Processamento do queijo coalho regional empregando leite pasteurizado e cultura lática endógena. Ciência e Tecnologia de Alimentos. 27 (1), 205-214. Recuperado em 15 de janeiro de 2008, de http://www.scielo.br/scielo.php?pid=S010120612007000100036\&script=sci_arttext.

Child, J., NG, S. H. \& Wong, C. (2002). Psychic distance and internationalization: evidence from Hong Kong firms. International Studies of Management \& Organizations, 32 (1), 35-56.

Coutinho, E. P. (2003, outubro). Denominação de Origem como ferramenta de qualificação vinculada ao espaço de produção. Anais do Encontro Nacional de Engenharia de Produção, Ouro Preto, MG, Brasil, 23.

DiMaggio, P. \& Powell, W. (1983, abril). The iron cage revisited: institucional isomorphism and collective rationality in organizational fields. American Sociological Review, 48 (2), 147-160.

http://dx.doi.org/10.2307/2095101

Du Gay, P., Hall, S., Janes, L., Mackay, H. \& Negus, K. (1997). Doing cultural studies: the story of the Sony Walkman. Londres: Sage Publications Ltd.

Duarte, D. A. M. (1999). Listeria sp. em queijo de coalho. Monografia de Especialização em Controle de Qualidade de Alimentos, Universidade Federal de Pernambuco, Recife, PE, 1999.

Dullius, P. R., Froehlich, J. M. \& Vendruscolo, R. (2008, julho). Identidade e desenvolvimento territorial - Estudo das experiências de indicações geográficas no estado do RS. Anais do Congresso da Sociedade Brasileira de Economia, Administração e Sociologia Rural, Rio Branco, AC, 46.

Etmad, H. \& Wright, R. W. (1999, março). Internationalization of SMEs: Management responses to a changing environment. Journal of International Marketing. 7 (4), 4-10.

Gadamer, H-G. (1999). Verdade e método: traços fundamentais de uma hermenêutica filosófica . 3. ed. Petrópolis: Vozes.

Gonçalves, M. F. W. (2007). Propriedade industrial e a proteção dos nomes geográficos: Indicações geográficas, indicações de procedência e denominações de origem. Curitiba: Juruá, 2007.

Gurgel, V. (2006). Aspectos jurídicos da Indicação Geográfica. In L, V. \& Braga, C. Valorização de Produtos com Diferencial de qualidade e identidade: Indicações geográficas e certificações para competitividade nos negócios. Brasília: SEBRAE.

Hall, S. (2006). Da diáspora: identidade e mediações culturais. Belo Horizonte: Editora da UFMG. 
A Estratégia de Internacionalização de Negócios na Perspectiva da Tradução Cultural: O Caso da Indicação Geográfica no Agronegócio

Hamlin, C. L. (1998, julho/dezembro). A Hermenêutica Romântica de Wilhelm Dilthey. Estudos de Sociologia. 4 (2), 85-98.

Henry, J. \& Walker, D. (1994). Managing Innovation. London: Sage Publications.

Hisrich, R. D. \& Peters, M. P. (2004). Empreendedorismo (5 a ed). Porto Alegre: Bookman.

Hitt, M. A., Ireland, R. D. \& Hoskisson, R. E. (2001). Strategic management: competitiveness and globalization. Ohio: South-Western College Publishing.

Johanson, J. \& Vahlne, J. E. (1997). The Internationalization Process of the Firm - A Model of Knowledge Development and Increasing Foreign Market Commitments. Journal of International Business Studies. 8 (1), 23-32.

http://dx.doi.org/10.1057/palgrave.jibs.8490676

Johnson, R. (2006). O que é, afinal, Estudos Culturais? In Silva, T. T. (org.). O que é, afinal, Estudos Culturais? ( $3^{\mathrm{a}}$ ed.). Belo Horizonte: Autêntica.

Lazzarotto, N. de F. (1999) Estudo sobre o mercado de certificações em alimentos no Brasil. Anais do IX Seminário Internacional PENSA em Agribusiness. Águas de São Pedro, SP, 9.

Lei $n^{\circ} 9.279$, de 14 de maio de 1996. (1996). Regula direitos e obrigações relativos à propriedade industrial. Diário Oficial [da República Federativa do Brasil], Brasília, 1996.

Lea, L., Lages, V. \& Braga, C. (2005). Indicações geográficas: a competitividade baseada na diferenciação qualitativa de produtos e serviços. In Lea, L., Lages, V. \& Braga, C (orgs.). Valorização de produtos com diferencial de qualidade e identidade: indicação geográfica $e$ certificações para competitividade nos negócios. Brasília: SEBRAE.

Merriam, S. B. (1998). Qualitative research and case study applications in education. Josey-Bass. California.

Minayo, M. C. de S. (2007). O desafio do conhecimento: Pesquisa qualitativa em saúde (10 a ed). São Paulo: Hucitec.

Moen, Ø. \& Servais, P. (2002). Born Global or Gradual Global? Examining the Export Behavior of Small and Medium-Sized Enterprises. Journal of International Marketing. 10 (3), 49-72. http://dx.doi.org/10.1509/jimk.10.3.49.19540

Moen, Ø. (2002). The Born Globals. International Marketing Reviews. 19 (2-3), 156-175.

http://dx.doi.org/10.1108/02651330210425015

Revista Ibero-Americana de Estratégia - RIAE, São Paulo, v. 9, n. 2, p. 75-98, mai./ago. 2010. 
Morais, C. M. M. (1995). Processamento artesanal do queijo de colho de Pernambuco: uma análise de perigos. Dissertação de Mestrado em Nutrição, Universidade Federal de Pernambuco, Recife, PE, Brasil.

Munck, A. V. (2004). Queijo de coalho: Princípios básicos da fabricação. Revista do Instituto de Laticínio Cândido Tostes. 59 (339), 13-15.

Ortiz, R. (2007). Mundialização e Cultura. São Paulo: Brasiliense.

Paim, I., Nehmy, R. M. Q. \& Guimarães, C. G. (jan/jun. 1996). Problematização do conceito "Qualidade" da informação. Perspectivas em Ciências da Informação, Belo Horizonte, 1 (1). 111-119.

Petithuguenin, P. (2006). Apresentação. In Lagares, L., Lages, V. \& Braga, C. Valorização de Produtos com Diferencial de qualidade e identidade: Indicações geográficas e certificações para competitividade nos negócios. Brasília: SEBRAE.

Rocha, A. de. (2002). A Internacionalização das Empresas Brasileiras: Estudos de Gestão Internacional. Rio de Janeiro: Mauad.

Serviço Brasileiro de Apoio às Micro e Pequenas Empresas. (2007a). Um queijo pernambucano com nome e sobrenome. Revista SEBRAE Agronegócios. 6, 16-17.

Serviço Brasileiro de Apoio às Micro e Pequenas Empresas. (2007, setembro, b). Pernambuco trabalha na indicação geográfica do queijo coalho. Brasília. Recuperado em 10 de dezembro, 2008 de www.interjornal.com.br.

Serviço Brasileiro de Apoio às Micro e Pequenas Empresas. (2006, maio). Queijo coalho de Pernambuco é alvo de ações para certificação. Brasília. Recuperado em m 10 de dezembro, 2008 de www.interjornal.com.br.

Silva, T. T. (2000). A produção social da identidade e da diferença. In Silva, T. T. (org). Identidade e diferença: a perspectiva dos Estudos Culturais. Petrópolis, RJ: Vozes.

Stiglitz, J.E. (2003). Globalization and its Discontents. Nova York: W.W. Norton \& Company.

Slater, M. D. \& Rouner, D. (1996). How message evaluation and source attributes may influence credibility assessment and belief change. Journalism and Mass Communication Quarterly, Columbia, 73 (4), 974-991.

Thompson, J. B. (2002). Ideologia e cultura moderna: teoria social crítica na era dos meios de comunicação de massa. Petrópolis: Vozes.

Valença, P. J. S. (2005). História da Pecuária Leiteira em Pernambuco. Recife: Coqueiro. 
A Estratégia de Internacionalização de Negócios na Perspectiva da Tradução Cultural: O Caso da Indicação Geográfica no Agronegócio

Veiga-Neto, A. (2000). Michel Foucault e os Estudos Culturais. In. Costa, M. Estudos Culturais em Educação: mídia, arquitetura, brinquedo, biologia, literatura, cinema... Porto Alegre: Ed. Universidade/UFRGS.

Recebido: 24/06/2010

Aprovado: 04/09/2010

\footnotetext{
${ }^{\mathrm{i}}$ A teoria OLI argumenta que a atuação no estrangeiro pode ser explicada conforme três vantagens auferidas a empresa: 1) Vantagem da Firma (O - Ownership); 2) Vantagem de Localização (L); e 3) Vantagem de Internacionalização (I).

ii Ao longo dos anos, o conceito de distância psíquica vem sendo refinado e aproximado de um conceito que evidencia as divergências de cunho socioculturais entre as partes envolvidas no negócio.

iii $\mathrm{O}$ nome geográfico deve identificar um determinado espaço na geografia que evoque o local ou região de onde o produto é extraído, fabricado, produzido ou onde há prestação de serviço. Isso significa que a constituição do termo geográfico não necessita ser a denominação geopolítica do local (Gonçalves, 2007).

${ }^{i v}$ Códigos desenraizados são códigos mundialmente conhecidos, os quais não se podem identificar sua origem.

${ }^{\mathrm{v}}$ Leite in natura, sem ser pasteurizado.

${ }^{\text {vi }}$ Pedaços do estômago de animais jovens (mocó, preá, cabrito, bezerro)

${ }^{v i i}$ Entende-se por hibridação "os processos socioculturais nos quais estruturas ou práticas discretas, que existiam de forma separada, se combinam para gerar novas estruturas, objetos e práticas" (Canclini, 2003, p. 19).
} 